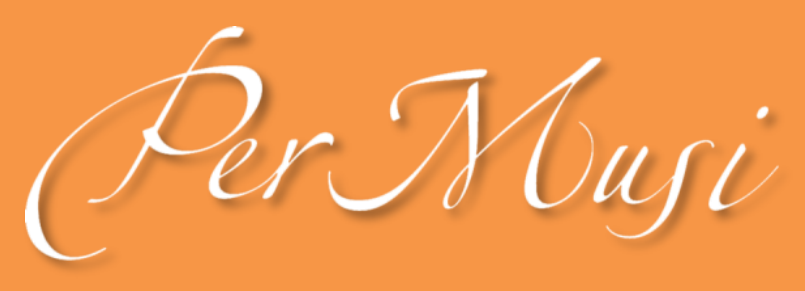

eISSN 2317-6377

\title{
Mimésis, géstica e as "origens" da escrita neumática gregoriana em Zu einer Theorie der musikalischen Reproduktion de Adorno (breves notas)
}

\author{
Alberto Medina de Seiça \\ https://orcid.org/0000-0002-4023-0164 \\ CESEM, Faculdade de Ciências Sociais e Humanas, Universidade Nova de Lisboa \\ albertoseica@fcsh.unl.pt \\ SCIENTIFIC ARTICLE \\ Submitted date: 19 oct 2020 \\ Final approval date: 09 dec 2020
}

Resumo: Na investigação musicológica sobre as origens, difusão e funções dos primeiros sistemas de escrita musical no contexto do repertório gregoriano, a perspectiva paleográfica tem assumido um papel essencial. Mas é claro que muitas outras metodologias e abordagens teoréticas concorrem para densificar o horizonte de compreensão da Musicologia histórica. Nestas notas, procuramos considerar a leitura que Theodor Adorno, no seu projecto inacabado "Zu einer Theorie der musikalischen Reproduktion", faz da emergência da notação musical. Reflectindo sobre as especificidades do sistema notacional, Adorno compreende-o à luz do nuclear operador conceptual de Mimésis. Apesar da progressiva racionalização da música ter esbatido a originária dimensão mimética, ela perduraria de forma latente nos sinais gráficos, entendidos como "imagens de gestos" e como instrumentos de controle social.

Palavras-chave: Adorno; Notação neumática; Mimésis; Quironomia.

TITLE: MIMESIS, GESTURES AND THE ORIGIN OF NEUMES IN ADORNO'S TOWARDS A THEORY OF MUSICAL REPRODUCTION (BRIEF REMARKS)

Abstract: Although the paleographical approach remains essential in the scholarly research focused on the origins, dissemination, and functions of the earliest notational systems used in medieval plainsong, historical Musicology is open to new methodologies. This article seeks to analyse some topics about the origins of chant notation from the perspective of the critical theory of Theodor W. Adorno. In his unfinished "Towards a Theory of Musical Reproduction", Adorno reflected on the specificities of the notational system, which he sought to comprehend in light of the nuclear concept of Mimesis. For him, "the musical symbols chosen to wrest the music are images of gestures", serving the function of social control. Nonetheless the progressive rationalization of music (indispensable for its aesthetic autonomy) has faded its mimetic dimension, the former continues to be remarkable on the graphic signs. It seems important to critically (re)adress this challenging and interpellant theoretical discourse.

Keywords: Adorno; Neumatic notation; Mimesis; Cheironomy. 


\section{Mimésis, géstica e as "origens" da escrita neumática gregoriana em $\mathrm{Zu}$ einer Theorie der musikalischen Reproduktion de Adorno (breves notas)}

Alberto Medina de Seiça, CESEM - FCSH, Universidade Nova de Lisboa, albertoseica@fcsh.unl.pt

Percussoris ad instar manum vox erigitur. (Aurelianus Reomensis. Musica Disciplina - séc. IX)

Die musikalischen Zeichen, welche die Musik der Vieldeutigkeit und Vergänglichkeit des Gestus entwanden, sind dafür Bilder von Gesten. (Theodor W. Adorno. Zu einer Theorie der musikalischen Reproduktion - séc. XX)

1. $* * *$

É bem conhecida a classificação das artes em duas categorias fundamentais: artes do espaço ou do repouso; artes do tempo ou do movimento. Esta "arrumação" conceptual, herdada já da antiguidade (Mocquereau 1908, 25-27), e tão simples, trivial quase, na sua formulação, densifica-se problematicamente em todas as dimensões do fenómeno artístico (produção, reprodução, distribuição, consumo). Nessa partição está (também) pressuposta (ou desvelada) uma diversa forma de abordagem aos "objectos", às "obras", exprimindo paradigmas compreensivos não inteiramente sobreponíveis ${ }^{1}$. Nas artes do espaço: pintura, escultura, arquitectura, a obra oferece-se ao observador na sua globalidade, o mesmo vale por dizer, numa síntese já realizada - quando olhamos a Mona Lisa ou a fachada de uma catedral, a "imagem" revela-se na sua completude à observação-fruição estética. O poeta português António Gedeão disse-o, em inspirada fulguração:

\footnotetext{
* [Nota do editor: O autor optou por escrever português europeu na versão anterior ao Acordo Ortográfico de 1990].

** Recordamos um admirável Seminário de Doutoramento leccionado pelo Prof. Doutor Mário Vieira de Carvalho em torno do pensamento de Adorno - possam estas páginas não desmerecer do muito que Lhe devem.

${ }^{1}$ Com o que fica dito procuramos apenas evocar modos de aproximação ao fenómeno artístico e não afirmar qualquer diferenciação ôntica entre "tipos" ou "categorias" de artes, problema que extravasa as intenções e possibilidades deste texto. Sobre as dimensões de "temporalidade" e "espacialização" na arte, $v$. o ensaio de Adorno, "Über einige Relationen zwischen Musik und Malerei", em que à recusa da pseudomorfose niveladora das expressões artísticas se contrapõe o processo dialéctico de convergência entre artes temporais e espaciais (Adorno 1978a).
} 
A catedral de Burgos tem trinta metros de altura

e as pupilas dos meus olhos dois milímetros de abertura.

Olha a catedral de Burgos com trinta metros de altura!

A partir desta "imagem-síntese" que se nos apresenta em simultaneidade ${ }^{2}$, evolui-se para o processo analítico, decompondo o conjunto global em fragmentos ou elementos parcelares, fixando a atenção no pormenor do sorriso enigmático e do olhar da Gioconda ou nas feéricas torres da catedral espanhola.

Nas artes do tempo ou do movimento ${ }^{3}$, como a música, a dança, a mímica, é outra a chave-de-leitura: nestas modalidades, a obra nunca se mostra acessível num só instante, pois a sua apreensão desenvolve-se num plano dinâmico. Quando escutamos um trecho musical ou vemos uma dança, apenas nos vão chegando fragmentos, elementos constitutivos de um processo que parece ter uma unidade superior, que os congrega e transcende, mas unidade que jamais podemos fruir por inteiro num só momento. Instanciação equivale a dissolução. No preciso átimo em que a nota musical é emitida ou o gesto dançantemímico se move no ar já não se podem de novo repetir, "imergindo" na corrente que flui para o passado praeterfluit in tempore praeteritum, como escreveu Santo Agostinho (De Ordine, 2.14.41). Cada música, cada dança, em rigor, só ocorrem uma única vez: no instante singular do acontecer, aquele instante que no próprio presente se dissolve em memória e que já não permite ao poeta beijar o gesto da tocadora de harpa (o tempo), mas apenas as suas mãos (o espaço) ${ }^{4}$. Nesta medida, a "compreensão", nas artes temporais, opera-se em caminho inverso ao seguido nas artes do repouso, partindo-se da análise, ou seja, dos fragmentos ou elementos percepcionados em cada momento, rumo à síntese, à visão de conjunto em que se procura conferir um qualquer sentido unificador a esses fragmentos, síntese que lhes possibilita, de algum modo, o "tempo liberto da temporalidade", na bela fórmula de Steiner $(1993,35)$. Sendo arte do tempo, volátil por definição, a música move-se num instável equilíbrio entre a voragem da definitiva dissolução e o desejo (potência) de perpetuação para lá do estrito acto-momento performativo, em que resiste somente porque se reitera. Neste horizonte, é manifesto que a invenção de sistemas de signos em ordem a "conservar e transmitir a ideia musical" (sistemas de notação) constituiu uma inestimável aquisição cultural, ao permitir ampliar a capacidade reiterativa da música - a sua aura de ressonância para além do som 5 .

\footnotetext{
2 "Im Bild ist alles gleichzeitig" (Adorno 1978a, 631).

3 "Artes energéticas", na expressão de Riemann $(1919,8)$, ou seja, aquelas em que a obra artística se manifesta, perante os olhos e os ouvidos, como um fragmento da vida real que se desenrola no tempo ("energischen Künste, d. h. der Kunstwerk als ein Stück wirkliches Leben vor Auge und Ohr im zeitlichen Geschehen entwickelnden Künste").

${ }^{4}$ Evoca-se o famoso poema de Fernando Pessoa: "Ó tocadora de harpa, se eu beijasse / Teu gesto, sem beijar as tuas mãos!, / E, beijando-o, descesse pelos desvãos / Do sonho, até que enfim eu o encontrasse / Tornado Puro Gesto [...] / Caverna em estalactites o teu gesto... / Não poder eu prendê-lo, fazer mais / Que vê-lo e que perdê-lo!... E o sonho é o resto...".

${ }^{5}$ Claro que esta "sedimentação notacional", esta dimensão "espacializada" da música (na partitura, no suporte informacional), entre muitas outras questões, implica desde logo o complexo problema da articulação entre o "texto musical" e a sua realização performativa. Como tem sido acentuado, os sistemas notacionais, mesmo os mais complexos, não traduzem por inteiro o conteúdo de que constituem suporte comunicacional (Boorman 2001; Adorno 2001, 215-221; Fubini 2004). Nem sempre, porém, a musicologia histórica tem conseguido manter-se imune ao fascínio do texto notado, hipostasiado enquanto expressão material (ou espacial ou identitária) da obra como fetiche (Adorno 2001, 89), com a consequente
} 
No contexto da música ocidental, o surgir da escrita musical é decisivamente um fenómeno medievo associado ao canto litúrgico; e representou, como realça Susan Rankin, um salto enorme no quadro global da literacia (Rankin 2018, 65) ${ }^{6}$. Embora os contornos históricos se mostrem assaz imprecisos em muitos pontos, o percurso científico sobre as primeiras formas documentadas de notação é, a todos os títulos, notável. Nesse caminho, a investigação paleográfica tem realizado um papel fundamental, procurando clarificar, inter alia, as questões fulcrais de datação, morfologia dos signos, ângulo do ductus, conexões entre manuscritos, identificação de scriptoria (cf. Rankin 2018, 50-54) ${ }^{7}$. Mas o horizonte de compreensão beneficia ainda de outras abordagens, seja situando as "novas técnicas gráficas" no contexto das representações e dos mecanismos de contacto cultural, seja focando as funções sociais do livro ou fazendo apelo à história das instituições e das formas litúrgicas, à documentação administrativa e diplomática, às crónicas e outros registos literários ou iconográficos, e aos contributos da etnomusicologia (Jeffery 1992; Levy 1987b; Greyer 2003; Rankin 2018) ${ }^{8}$. Como se entende, a transversalidade de saberes e metodologias reveste-se de primacial importância e deve ser, em nosso entender, decididamente reforçada numa abertura da musicologia medieval a modos diversos de pensar os problemas, não apenas por causa dos eventuais "resultados" em termos de "informação disponível", mas ainda, e muito, pelo desafio epistémico aí implicado - na escuta de vozes dissonantes do milieu corrente de cada disciplina singular questiona-se a respectiva autossuficiência discursiva, refractária ao diálogo e à crítica ${ }^{9}$.

desvalorização da performance que, pelo seu carácter efémero, se mostraria refractária à análise e à sistematização. Dito com Treitler $(2011,85)$, "the focus has been on music as object, not as process". Sobre o problema da interpenetração score / performance, veja-se ainda, com profundidade, Cook 2013. Refirase, de todo o modo, que se "La partition est inapte à représenter dans l'espace la temporalité de la musique et elle ne pourra jamais que symboliser le caractere essentiellement temporel de la musique" (Fubini 2004, 23), também a interpretação (qualquer interpretação concreta) não esgota as virtualidades da obra, as suas "multifarious potentialities", na expressão de Paddinson $(2004,158)$.

6 "To move from a culture of writing in which the sound of those who sing was experienced in the moment of hearing, but represented in writing only in the form of the words sung, to one in which a highly developed system of graphic marks could be used to represent musical sounds was surely a big jump" (Rankin 2018, 65).

7 Não se deve subestimar estes contributos: embora a paleografia não pretenda responder a todas as dúvidas suscitadas pelo surgimento e difusão da notação, sem dados paleográficos fiáveis, é grande o perigo de resvalar para a mera especulação.

8 Como se sabe, a consideração dos fenómenos especificamente escriturísticos tem beneficiado de metodologias que vão além da mais usual leitura paleográfica e se situam já no domínio da análise semiótica, ou seja, abordagens centradas nas relações funcionais entre os sistemas de signos e aquilo que significam dentro dos específicos contextos em que esses signos operam. Nesta linha, Leo Treitler convoca o operador "situação comunicacional" de R. Jakobson para interrogar as funções desempenhadas pelos elementos gráficos no quadro complexivo de factores integrantes do evento comunicacional (speech event); integrando-o, num segundo e complementar momento, com a classificação de Charles Sanders Peirce sobre os modos de representação funcional dos signos: simbólico, icónico, indexical, que Treitler aplica na interpretação semiótica das grafias dos antigos manuscritos musicais (Treitler 1982). Expressando dúvidas sobre o alcance desta proposta de Treitler, v. Rankin (2018, 62-63).

${ }^{9}$ Neste sentido lemos o desafio que Aubert, a propósito da historiografia da neumática, faz aos "current scholars working with neumes to develop a sharper awareness of their own discourses and of how their 
E reside aqui o principal motor deste artigo: ouvir a interpelação dialógica de uma voz que raramente surgirá na investigação especializada em torno da notação neumática - Theodor W. Adorno (1903-1969) ${ }^{10}$. Na verdade, a simples invocação de Adorno em matéria de canto gregoriano causa surpresa - que ligação haverá entre o crítico do modernismo, da indústria cultural e da sociedade administrada, o controverso autor da Philosophie der neuen Musik, o analista atento de Beethoven e Mahler, e o estudo das antigas melodias do cantochão? É certo que Adorno já havia considerado alguns aspectos da chamada "música antiga", ao censurar tendências interpretativas que pretendendo promover, em nome de uma suposta "autenticidade", a restauração absoluta do passado, se alheavam do tempo presente, anulando a capacidade crítica da música em face das estruturas sociais ${ }^{11}$. Por outro lado, encontram-se na vasta obra algumas referências esparsas ao sentido funcional dos neumas ${ }^{12}$. Todavia, a publicação póstuma dos materiais coligidos em ordem a um (inconcluso) estudo sobre a interpretação musical - Zu einer Theorie der musikalischen Reproduktion: Aufzeichnungen, ein Entwurf und zwei Schemata ${ }^{13}$ - trouxe à luz um conjunto de reflexões que abordam com mais demora a neumática gregoriana.

É neste horizonte específico que as notas seguintes se situam, procurando reflectir sobre dois concretos tópicos da leitura adorniana: a questão da invenção dos sinais gráficos (a "origem dos neumas") e, em articulação, a questão da sua funcionalidade sociocultural, ou seja, das funções instrumentais ocupadas

scholarly production is affected by the frequently tacit notions that underlie their research" (Aubert 2012, 84).

10 Para dar apenas dois exemplos de obras recentes da musicologia medieval em que, por serem outros os propósitos, é escusado procurar uma referência a Adorno, mencione-se a profunda investigação de Susan Rankin Writing Sounds in Carolingian Europe: The Invention of Musical Notation (Rankin, 2018) ou a ampla Cambridge History of Medieval Music (cf. Everist e Kelly, 2018). Isto dito não significa de modo algum que a reflexão adorniana sobre os neumas medievais seja desconhecida. Veja-se, também como exemplo, a análise feita por Frank Kuehn (2010, 75 ss).

${ }^{11}$ Recorde-se o famoso ensaio Bach gegen sein Liebhaber verteidigt publicado em 1951 e a crítica ao pensamento objectivista que se ia tornando dominante na interpretação da música antiga. Para uma breve análise da posição de Adorno quanto ao problema da chamada "interpretação autêntica" ver Dreyfus (1983, 300-304); Carvalho (2007, 22 ss).

12 Veja-se, por exemplo, Adorno 1978a, 632, a propósito da carácter essencial e não meramente incidental da notação, realçando a "qualitativa relação da música com os signos visíveis (qualitative Beziehung der Musik auf ihre sichtbaren Signa), em que anota: "a representação gráfica nunca é portanto um mero signo para a música, mas antes tem com ela muitas semelhanças, como ocorreu outrora com os neumas ("Die graphische Repräsentation ist denn auch nie bloß Zeichen für Musik, sondern immer auch in manchem ihr ähnlich wie einst die Neumen", sublinhado nosso).

${ }^{13}$ A tradução mais ajustada seria Para uma teoria da reprodução musica: notas, um esboço e dois esquemas. Aliás, a edição inglesa de 2006 intitula-se Towards a Theory of Musical Reproduction: Notes, a Draft, and two Schemata. Na sua dissertação de 2010, centrada precisamente sobre a Theorie, Frank Kuehn usa a palavra "reprodução". A opção entre "interpretação" / "reprodução", no qudro do pensamento de Adorno, não é estritamente terminológica, mas tem relevância semântica. Foram duas as hipóteses de título anotadas por Adorno: Die wahre Aufführung (A verdadeira execução / interpretação) e Reproduktionstheorie. Ein musikphilosophischer Versuch (Teoria da reprodução. Uma investigação músicofilosófica). Preferiu-se aqui o termo "interpretação" (por vezes, performance), para maior imediação compreensiva, em sintonia, diga-se, com outros estudos, v.g. Cecchi 2017: To imitate all that is hidden. The place of mimesis in Adorno's theory of musical performance; Carvalho 2007: A Partitura como Espírito Sedimentado: Em Torno da Teoria da Interpretação Musical de Adorno; Carvalho 2009: Meaning, Mimesis, Idiom: On Adorno's Theory of Musical Performance. 
pela notação no contexto social que a produziu. Assim, e depois de sucinta apresentação do livro (número 3), foca-se a questão da escrita musical no confronto com a linguagem verbal (número 4), a relevância do elemento mimético densificado nos neumas-gestos (números 5 e 7), e a função social associada ao sistema notacional (números 6 e 7). Como opção metódica assumida, e uma vez que no impulso inicial esteve a (nossa) escuta, convocou-se com frequência para o percurso a própria voz de Adorno ${ }^{14}$. Ampliando o horizonte dialógico, a segunda secção (a partir do número 8) visa uma brevíssima contextualização da emergência dos neumas gregorianos à luz da investigação musicológica.

3.

A Theorie der musikalischen Reproduktion foi publicada em 2001, mais de trinta anos após a morte de Adorno. Como esclarece o organizador, Henri Lonitz (2001, 381-385), o livro inclui trechos escritos em fases distintas. Embora a ideia inicial viesse já da década de 1920 (um primeiro esquema é de 1927), partes significativas são datáveis entre 1946 e 1949 - incluindo o Entwurf, o esboço preliminar da obra - e entre 1953 e finais de 1959. Esta dispersão temporal encontra paralelo no carácter fragmentário dos próprios conteúdos: um número significativo de notas de variável extensão, alguns esquemas, remissões para fontes que Adorno ia estudando. Mesmo o Entwurf, mais articulado, constitui apenas um primeiro ensaio de uma obra que não recebeu das mãos de Adorno a sua forma derradeira. O carácter exploratório é, aliás, expressamente assumido pelo autor em diversas anotações marginais, reconhecendo a necessidade de aclarar ou desenvolver passagens menos conseguidas (cf. p. 224: schwach, ausführen u. viel tiefer fassen; schwach $u$. dunkel) ou, ainda, de dar maior sustentação bibliográfica às teses avançadas (cf. p. 70, ao inserir que faltam referências: Belege). Com isto não se pretende significar que os textos tenham menos relevo intrínseco ${ }^{15}$, mas apenas recordar que o volume será (definitivamente) provisório e incompleto, pelo que censurar incoerências num livro que não chegou a existir pode resultar de erro metodológico do leitor, não de Adorno.

4.

Reflectindo sobre a teoria da interpretação musical (musikalischen Interpretation), Adorno enfatiza a questão da natureza do texto musical (was ist ein musikalischer Text?), o que envolve compreender a relação entre notação e escrita, entre música e linguagem ${ }^{16}$. Como sublinha, "à semelhança da escrita para a linguagem, a escrita musical é um sistema de signos" (Adorno 2001, 221) ${ }^{17}$. Todavia, os signos verbais e a linguagem em si mesma pertencem a um sistema homogéneo, enquanto a música e a sua escrita

\footnotetext{
${ }^{14}$ As traduções para português são do autor deste artigo. Na bibliografia final, depois da referência original usada, indicam-se versões em língua inglesa.

15 Como justamente assinala Mário Vieira de Carvalho (2007, 15), o carácter fragmentário da obra radicaliza a sua interpelação teórica, "conferindo-Ihe uma energia epistemológica verdadeiramente rara, que corta transversalmente diferentes esferas da estética - em especial, é claro, da estética musical envolvendo a criação, a mediação e a recepção". Também Barry $(2009,89)$ realça que "the aphoristic condition of the text is not just Adorno's work-in-progress, but also a way for him to address some specific questions from different angles".

${ }^{16}$ Adorno 2001, 11: "Wie verhält sich die Notenschrift zur Schrift? Eine der zentralsten Fragen, unlösbar von der: wie verhält Musik sich zur Sprache?".

17 Adorno 2001, 221: "Gleich der sprachlichen ist die musikalische Schrift ein Zeichensystem".
} 
pertencem a dois sistemas diversos ${ }^{18}$. Os signos musicais, mesmo nos casos em que são derivados da linguagem (notação alfabética), não se combinam para formar unidades que refiram objectos, pelo que a "escrita musical é vazia de intenção, uma nomenclatura cega; e as unidades de sentido em que a música se desenvolve nada têm em comum com a intencionalidade: a música é uma linguagem não-intencional” (Adorno 2001, 221) ${ }^{19}$. Note-se que esta ausência de cunho intencional não retira à escrita musical uma "consistência lógica e articulação" paralelas às da linguagem verbal. Ela evidencia, porém, que o elemento característico da notação reside num outro elemento, não-intencional mas representativo (hypokritike): o elemento mimético ${ }^{20}$.

5.

A densidade e a importância do conceito de mimésis no contexto global do pensamento adorniano têm sido profundamente investigadas ( $c f$. Cahn 1984; Duarte 1993; Paddison 2010) e seria inviável ponderar aqui as múltiplas ramificações por que se desdobra ou sequer as suas coordenadas teoréticas fundamentais ${ }^{21}$. No quadro em que nos situamos - a origem e o sentido funcional da neumática na obra Theorie der musikalischen Reproduktion - há de todo o modo alguns aspectos a sublinhar. Desde logo, importa acentuar a circunstância de que em Adorno a dimensão mimética se situa em "estruturas" profundas da hominização. Para o autor (cf. Adorno 2001, 223), o elemento mimético é intrínseco à (essência da) música desde a sua origem (der Musik als solcher wohnt das Mimische inne). Além disso, continua, ainda que não seja determinável qual o grau que a replicação (Nachahmung) dos sons da natureza teve na origem da música, é seguro que ela se fez por meio de gestos, sejam os do trabalho ou da dança, inserindo-se na esfera do uso mágico (magischen Gebrauchs), que vai mesmo para lá do sincretismo (unidade de função: Einheit ihrer Funktion) entre música, dança e mímica realizado na prática cultual

${ }^{18} \mathrm{~A}$ heterogeneidade entre os sistemas sígnicos reflecte-se sobre a interpretação. Interpretar a linguagem significa compreender a linguagem (Sprache verstehen); intepretar a música significa fazer música (Musik machen). Cf. Adorno, 1978b, 651.

19 “[...] Die musikalische Schriftsprache ist eine ohne Intention, gleichsam eine blinde Nomenklatur, und die Einheiten des Sinnes, in denen Musik selber sich bewegt, haben mit Intentionalität nichts gemein: Musik ist eine intentionslose Sprache"... (Adorno 2001, 221) Note-se que esta "não-intencionalidade" não significa uma carência ou imperfeição do texto musical em face do texto verbal. Para Adorno, trata-se de um cunho constitutivo do sistema sígnico-musical, que lhe confere dignidade autónoma. A formulação densa de uma das Aufzeichnungen revela-o claramente: "Die Würde des musikalischen Textes ist seine Intentionslosigkeit" (Adorno, 2001, 13). E como "a música constitui uma linguagem não-intencional, o carácter significacional da sua escrita (a diferença entre signo e designado) é extremado até ao ponto de uma ruptura qualitativa" (Adorno 2001, 222: "Gerade weil Musik eine intentioslose Sprache ausmacht, ist der significative Charakter ihrer Schrift, die Differenz von Zeichen und Bezeichnetem, um qualitativen Bruch gesteigert").

${ }^{20}$ Cf. Adorno (2001, 222): "ihr [die musikalischen Schrift] Ursprung in einem anderen Elemente vermutet werden als dem intentionalen. Das ist aber die hypokritike [...]. Es ist das mimetische Element".

${ }^{21}$ Muito menos se poderia considerar nestes apontamentos o relevo autónomo que o tema da mimésis (ou das suas distintas conceptualizações) tem implicado na vasta reflexão filosófica e histórica sobre os fenómenos artísticos, espelhada em tantos estudos. Permita-se realçar, ainda assim, o recente trabalho de Eduardo Henrik Aubert, dedicado à liturgia e notação no contexto romano-franco, e que convoca, com profundidade, o conceito de mimésis, sobretudo a partir da obra seminal de E. Auerbach (cf. Aubert 2013). Com relevo, v., ainda, Treitler 2011 e 2012. 
(kultische Übung). A música é mímica do invisível (Mimikry ans unsichtbare); tem natureza (Wesen) mágico-mimética (Adorno 2001, 224) ${ }^{22}$.

Todavia, e eis um segundo ponto, aquele (originário) carácter mimético foi sendo marginalizado (tornado tabu) no processo de racionalização que confere à música a sua autonomia estética (Adorno 2001, 224) ${ }^{23}$. É certo que a dimensão mimética como que se reintroduz na música (e nela permanece) por meio da notação, isto é, do sistema de signos que, sujeitando a música à objectivação, à reificação, não consegue sufocar por inteiro, no entanto, a sua matriz gestual: "os signos musicais, que procuram subtrair a música à ambiguidade e à transitoriedade do gesto, são, afinal, imagens de gestos" (Adorno 2001, 224) ${ }^{24}$. Paradoxalmente, todavia, a notação "géstica" comporta um "elemento objectivante, regulador da tradição e anti-expressivo", pois sendo fundada embora na mimésis, "na imagem visualmente solidificada do gesto musical" (Adorno 2001, 233) 25 $^{25}$ ao assumir-se espacialmente, como inscrição visiva de carácter pictórico, opõe-se à mimésis primordial (der primären Mimesis) ${ }^{26}$ - uma vez que, por meio da grafia, cada gesto musical surge em conexão simultânea com outros, ele deixa de ser um autêntico gesto, passando a eternizar no signo aquilo que é musicalmente transitório: o impulso mimético (cf. Adorno 2001, 245) 27.

De tudo isto resulta que, para Adorno, só na dialéctica com o elemento abstracto-significacional (abstractsignificatives Element) decorrente das notas-letras se abriu o caminho rumo à autonomia da obra musical. Nas suas palavras, "a genuína concreção musical, na qual o impulso mimético como tal subsiste, está

${ }^{22}$ Realçando esta dimensão da mimésis adorniana, veja-se já Cahn (1984, 32): “Adorno emphasizes the behavioral and almost sensual dimension of mimesis in mimicry and magic", que não se confunde com a imitação, e Paddison (1991, 272): "Using the concept of mimesis [...] Adorno was not returning to a literal understanding of the traditional aesthetic concept of mimesis as 'imitation of nature'. He used it instead in an almost anthropological, if not zoological or prehistorical, sense, as mimicking aspects of an often hostile environment in order to gain control of it or adapt to it, as a form of protection. Mimesis in this sense is akin to magic, and can also be understood as an earlier stage in the development of rationality itself". Cf., ainda, a síntese de Carvalho (2009, 86-88), situando a perspectiva adorniana num contexto mais amplo, com apelo à investigação de Knepler sobre a origem da música.

${ }^{23}$ Adorno (2001, 224): “[...] die Ausbildung der Musik als autonomer Kunst das mimische Moment [...] immer mehr an der Rand gedrängt, vielleicht tabuierte hat". Note-se, porém, que, como sublinha M. V. Carvalho $(2012,15)$, "Adorno sees in autonomous music and art in general just a chance to escape from the significational, to resist the ideology or false consciousness which falls insidiously throughout the discursive communication. To experience music as a chance for truth stands for being freed from the 'lie of meaning', the 'prison of language'".

24 "Die musikalischen Zeichen, welche die musik der Vieldeutigkeit und Vergänglichkeit des Gestus entwanden, sind dafür Bilder von Gesten" (Adorno 2001, 224). Na formulação de Paddison (1991, 272), "the language-character of music could be further formulated in the following terms: (1) through the increasing process of rationalization and domination of all aspects of its material, music becomes highly systematic; and (2) through the survival within it of pre-rational, magical elements, music also functions on a mimetic, gestural level which resists systematization".

25 "[...] das objectivierende, traditionsregelnde und in gewissen Sinn ausdrucksfeindliche Element der Notenschrift gerade auf Mimesis, dem optisch erstarrten Abbild der musikalische Geste beruht" (Adorno 2001, 233).

26 Cf. Adorno (2001, 245): "Der Bildcharakter der musikalischen Schrift, die Verräumlichung des Zeitverlaufs, ist der primären Mimesis geradezu entgegengesetzt".

27 "Das musikalische Zeichen verewigt das musikalisch Ephemere, das mimische Regung" (Adorno 2001, 245). 
impresso na escrita justamente por meio deste segundo elemento, abstracto-significacional: a notação alfabética" (Adorno 2001, 224) ${ }^{28}$. Daí que a dimensão especificamente gestual se vá esbatendo à medida que o nível abstracto-significacional da escrita se expande a fim de permitir o controle das estruturas polifónicas e harmónicas (cf. Carvalho 2007, 27) ${ }^{29}$. Com o uso dos neumas, a música surge na sua imediação (Unmittelbarkeit), nesse modo-de-ser um efémero presente (ephemeren Gegenwart) que se mostra indiferente à duração; ao invés, a imersão do elemento intencional na notação (aniquilando a música enquanto fenómeno natural), remete para a eternidade, para a duração que anula o aqui e o agora e expulsa (Bann), pela escrita, a representação mimética ( $c f$. Adorno 2001, 235) ${ }^{30}$. Daí resulta que "a história da notação musical representa uma tentativa de alcançar uma síntese entre não-ambiguidade e imediação" (Adorno 2001, 236) ${ }^{31}$. Na grafia, condensa-se a objectivação da música, a sua reificação por via da espacialização do fluxo temporal ${ }^{32}$. Por isso, continua, a "imortalização da música por meio da escrita contém um aspecto letal: aquilo que se fixa torna-se ao mesmo tempo irrecuperável [...] todo o fazermúsica é uma recherche du temps perdu" ${ }^{33}$. Esta tensão entre o que a notação pretende conseguir e aquilo que efectivamente pode realizar (Barry 2009, 93) está condensada na própria dialéctica do texto musical: "ser ao mesmo tempo um enigma insolúvel e o princípio da sua resolução" (Adorno 2001, 241) 34 . E não deixa de ser relevante que, numa nota, Adorno afirme que "todos os problemas da neumática estão contidos na notação moderna" e que a dificuldade em decifrar os neumas não decorra da nossa distanciação temporal, mas "porque se procura racionalisticamente algo que é falso: a não-ambiguidade" (Adorno 2001, 82) 35 .

28 "[...] wird ungekehrt die eigentliche musikalische Konkretion, in der mimetische Impuls als solcher fortlebt, der Schrift eingesenkt gerade durch ihr zweites, abstract-significatives Element, die Buchstabentonschrift" (Adorno 2001, 233). Como escreve Barry $(2009,93)$ : "like music's own dual nature of linguistics and mimesis, notation is both sign and symbol".

${ }^{29}$ Cf. Adorno (2001, 234): "Denn es erhellt, daß die Neumisierung, als reine Gestenschrift zur Festlegung selbst der primitivsten Mehrstimmigkeit im Organum untauglich war".

30 "Die Gestenschrift [...] beschwört Musik in ihrer Unmittelbarkeit, als Natur gleichsam, ruft sie zur ephemeren Gegenwart und ist unbekümmert um ihre Dauer. Der Intention geht es um Ewigkeit: sie tötet Musik als Naturphänomen, um sie gebrochen, als Geist, zu bewahren: das Überleben von Musik in ihrer Dauer setz die Abtötung ihres Jetzt und Hier, um in der Schrift den Bann von dessen mimischer Repräsentation voraus" (Adorno 2001, 235).

31 "Die Geschichte der Notenschrift ist der Versuch einer Synthesis von Eindeutigkeit und Unmittelbarkeit" (Adorno 2001, 236).

32 Cf. (Adorno 2011, 71): "Jedes Notenzeichen ist das Bildes eines Schages: die Objektivierung der Musik, das Umsetzen des Zeitverlaufs in einen räumlichen".

33 "Der Verewigung der Musik durch Schrift eignet ein tödliches Moment: was sie hält, wird zugleich unwiederbringlich. [...] Alles Musizieren ist ein recherche du temps perdu" (Adorno 2001, 228). Adorno enfatiza, ainda, o risco da espacialização: "verräumlichen heisst da sein: die absolute Gegenwart wäre zeitlos und nur das was ganz da ist, läßt sich beherrschen. Verräumlichung ist ihrem Inhalt nach Beherrschbarkeit" (Adorno 2001, 228). E, ainda, "durch die Schrift ist nicht nur das Vergangene zu vergegenwärtigen, sondern in der Vergegenwärtigung, dem 'Dasein' ist alles musikalische Material übersichtlich zu machen, zu ordnen, nach einheitlichen Prinzipien zu organisieren” (Adorno 2001, 229).

34 "Jede musikalische Text ist beides; prinzipiell unlösbares Rätsel und Prinzip zu seiner Lösung" (Adorno 2001, 241). Sobre esta resolução v. Carvalho $(2007,23)$.

35 "NB alle Probleme der Nuemisierung sind in der modernen Notation enthalten". "Der Schwierigkeiten der Dechiffrierung, weil man rationalistich nach etwas Falschem - der Eindeutigkeit sucht" (Adorno 2001, 82). 
A análise adorniana não se esgota numa "etiologia dos grafismos", isto é, na sua compreensão causal como imagens gésticas, mas revela, segundo Adorno, a tensão funcional e teleológica que a escrita musical, enquanto sistema organizado, introduz no tecido social. E com isto entramos no segundo tópico que referimos acima, no termo do número 2: qual o sentido funcional da notação neumática, que papel social veio desempenhar e "justificou" a sua invenção? A explicação mais imediata ou mais óbvia, de que a notação traduz um mecanismo auxiliar da memória (Gedächnitsstütze), evitando o esquecimento da música, é rejeitada por Adorno. Em seu entender, pensar deste modo implica uma leitura racionalista, uma projecção do quadro conceptual moderno para épocas culturais em que ele não tem cabimento ${ }^{36}$. Ora, inversamente, a "notação só representa uma ajuda da recordação e da memória na medida em que é sua inimiga, em que as destrói por meio da sua restauração" (Adorno 2001, 226) 37 . Ela não representa um meio inócuo de preservar algo fugaz (Adorno 2001, 70: harmloses Bewahren eines Flüchtigen), mas exprime uma alteração do estado-de-coisas prévio à constituição da memória, um tempo em que o agora e o antes (Jetzt und Früher) ainda não tinham sido rigidamente separados (Adorno 2001, 226). 0 signo musical não se oferece, destarte, como uma ferramenta mnemónica, mas espelha o desenvolvimento de compactas relações de hierarquia social (gesellschaftlicher Herrschaftsverhältnisse) ${ }^{38}$. Pela notação, gera-se um instrumento de dominação social, de disciplina e controle sobre os membros da comunidade, impedindo-os, como massa subjugada (unterworfene Masse), de modificar livremente a tradição (das Überlieferte) segundo as suas específicas necessidades expressivas, e obrigando-os a aprender por meio da repetição compulsiva (zwangshafter Wiederholung) práticas rigidamente fixadas em suportes escritos vinculativos (cf. Adorno 2001, 226) ${ }^{39}$. Por isso, a "notação desapodera a memória ao assisti-la: constitui o primeiro passo rumo à sua socialização" ${ }^{40}$. Embora a exposição sincopada da Theorie seja escassa em coordenadas históricas precisas, Adorno estabelece uma ligação entre a função disciplinadora da notação e o cristianismo, na medida em que neste a realidade creatural (kreatürliche) ou corporal da música se transmutou na linguagem da alma (Sprache der Seele) que exclui o corpo (Leib) como forma de o controlar $^{41}$. Não foi por um acaso, diz Adorno, que a intencionalidade emergiu na notação - ela exprime a cristianização da música ${ }^{42}$.

${ }^{36}$ Cf. Adorno 2001, 70: "Diese These ist rationalistisch, eine Projektion später Bedürfnisse in die Archaik", ideia retomada no Entwurf (p. 225), com a precisão de que que tal atitude decorre de uma "ilusão da sua universalidade"(Illusion ihrer Allmenschlichkeit).

37 "Die Notation ist Stütze der Erinnerung und des Gedächtnisses nur als dessen Feind, als seine Wiederherstellung durch Vernichtung" (Adorno 2001, 22).

${ }^{38}$ Sublinhando este aspecto, $v$. Carvalho 2007, 25.

${ }^{39}$ Cf. Adorno 2001, 226: "Was [...] von den Noten vollbracht war, ist weniger die Bewahrung eines ohnehin in Tradition Gegenwärtigen als vielmehr die Disziplinierung der traditionellen übung, welche die Gemeinde, also die unterworfene Masse, davon abhalten soll, im Sinn des eigenen Ausdruckbedürfnisses das Überlieferte zu modifizieren, sondern in dessen zwangshafter Wiederholung besser gehorchen zu lernen".

40 "Notation enteignet das Gedächtnis, indem sie ihm hilf: sie ist der erste Schritt zu seiner Vergesellschaftung"(Adorno 2001, 227).

${ }^{41}$ Cf. Adorno 2001, 235: "Wird die kreatürliche Musik dem cristlichen Zeitalter zur Sprache der Seele, deren Leib vergeht, die wegwirft, damit sie gewinnt [...]".

${ }^{42}$ Cf. Adorno 2001, 235: "Aber die Einbruch der Intentionalität in die musikalische Notation ist selber nicht zufällig. Er ist Ausdruck der Christianisierung der Musik". Destacando este ponto, v. Carvalho 2007, 27. 
Apesar do carácter preliminar das anotações de Adorno, elas dão-nos a conhecer, em diversos passos, parte do "estado-da-arte", com remissão explícita para fontes consultadas em determinadas matérias ${ }^{43}$. No ponto relativo ao surgimento histórico da notação, as referências basilares pertencem aos dois tomos iniciais do Handbuch der Musikgeschichte de Hugo Riemann. Em Riemann encontra a hipótese de já entre os gregos a notação ter uma origem quironómica, vale por dizer, constituir a tradução gráfica dos movimentos feitos com as mãos pelo "director do coro" ${ }^{44}$. Esta possibilidade ganharia mais consistência no tocante à escrita neumática medieval. Neste âmbito, e sempre por intermédio de Riemann, Adorno considera ainda as posições de Oskar Fleischer e André Mocquereau. Para Fleischer, a evolução da grafia musical de simples marcações dos acentos em direç̧ão a neumas mais complexos espelharia a prática do mestre do coro, que indicaria os movimentos melódicos mediante os gestos das mãos (Adorno 2001, $230 \mathrm{e}$ 83). A origem mimética da notação é acolhida, ainda mais amplamente, escreve Adorno, na tese de Mocquereau. Para o monge beneditino, a própria notação baseada nos acentos gramaticais, e não apenas a sua combinação posterior em figuras neumáticas mais complexas, representaria já uma imagem géstica: uma pictografia (Adorno 2001, 230 e 84).

Importa referir, ainda, que Adorno, na leitura da exposição de Riemann, não se limitou a sublinhar a questão da origem quironómica dos sinais gráficos no canto litúrgico medieval, mas realçou ainda a dimensão funcional da escrita neumática. Com efeito, na secção das Aufzeichnungen encontra-se uma remissão explícita para uma passagem do Handbuch que Adorno classifica como: "página extremamente importante" (äußerst wichtige Seite). Ora, nessa página, Riemann aponta como pressuposto dos neumas sem linhas o facto de eles se reportarem a um restrito número de melodias transmitidas por imitação no canto - mais do que fixar rigidamente cada elemento da linha melódica, a notação teria como finalidade o ajustamento adequado a cada texto (cf. Riemann 1920, 95) ${ }^{45}$. Do excerto, Adorno destaca alguns pontos: que os neumas pressupõem uma transmissão directa; e - aspecto primacial: Haupstelle - que a finalidade da neumática não é a fixação da melodia, mas sim a adaptação ao texto (cf. Adorno 2001,81$)^{46}$. E, em sintonia, na redaç̧ão menos esquemática do Entwurf, conclui: "a notação musical seria ao mesmo tempo

${ }^{43}$ Entre os autores mais vezes convocados expressamente, além de Hugo Riemann, de que se falará em texto, surgem Dorian, Wagner e, em medida mais discreta, Benjamim e Schoenberg. Sobre o "quadro referencial" de Adorno veja-se a análise de Cecchi (2017).

44 Veja-se as remissões de Adorno (2001, 78 e 230) para o texto de Riemann: "Es ist sogar nicht unmöglich, da $\beta$ die Neumenschrift selbst griechischen Ursprung ist und sich aus der Cheironomie, den Handbewegungen des die Melodiebewegung und die ihr entsprechenden Bewegungen des Chors leitenden Chordirigenten des Altertums entwicklet hat" (Riemann 1919, 31; Adorno cita a edição de 1923, neste ponto idêntica).

45 "Also erste Vorbedingung für eine gerechte Beurteilung des Wertes der Neumen ohne Linien ist die Annhame einer beschränkten Anzahl durch direkte Überlieferung mittels Vorsingens und Nachsingens weitergegeben Melodien; nicht die Festlegung dieser Melodien in einer jeden Einzelton bestimmenden Notierung ist ihr Zweck, sondern viermehr die besondere Art ihrer Anpassung auf den jedesmaligen Text" (Riemann 1920, 95).

46 "Neumen setzen unmittelbare Überlieferung voraus. Zweck der Neumierung: nicht Festlegung der Melodien sondern Anpassung auf Text (kultische Disziplin). Hauptstelle" (Adorno 2001, 81). 
uma imitação da referida quironomia, uma géstica em sentido literal, e a imagem de uma dimensão disciplinar, a regência do coro feita pelo maestro pré-histórico" (Adorno 2001, 230) ${ }^{47}$.

8.

Adorno não era medievalista - nem pretendeu assumir essa veste. A sua análise foca o presente, desvelando as fracturas do modelo cultural dominante e os riscos reais de instrumentalização da pessoa numa sociedade administrada; alargar o olhar à música do passado significa ainda um esforço para compreender dialecticamente o agora. A relação tensional entre texto musical e interpretação, por um lado, e a distrinça entre escrita verbal e sistema notacional, por outro, impelem-no a questionar a própria notação: quer na sua estrutura imanente de linguagem não-intencional, mimeticamente constituída (os signos da escrita musical são imagens de gestos); quer ainda na sua função social como mecanismo de controle e disciplina social. O problema das "origens" e "funções" dos signos musicais interpela por conseguinte a própria teoria crítica e foi essa interpelação que se procurou desenhar, embora em traços rápidos. Confrontar essa reflexão com a investigação musicológica que se ocupa das fases primevas da neumática exigiria desenvolvimentos aqui impossíveis, pela extensão do horizonte problemático e da consequente produção científica. Limitamo-nos, pois, a enumerar uns quantos tópicos desse complexo mapa compreensivo.

9.

Em primeiro lugar, parece relevante sublinhar que nem todos os registos notacionais pertencem à mesma "tipologia" ou cumprem a mesma função "musical". Em face dos testemunhos conservados, pode distinguir-se entre dois modelos fundamentais, consoante a destinação funcional das grafias e a sua intenção representativa. Por um lado, encontram-se tipos de escrita que permitem a determinação rigorosa das alturas melódicas, por meio de signos decorrentes sobretudo das letras do alfabeto grego ou latino. Este sistema de escrita (em que se destacam a notação alfabética e a notação dasiana) tem essencialmente um carácter especulativo ou didáctico e não se dirigia a orientar a execução concreta dos cantos litúrgicos ou a assegurar a sua difusão interpessoal; ela possibilitava a compreensão das relações intervalares e a estrutura modal das diversas obras (Phillips 2000; Hiley 2001; Kelly 2018, 239-241). O segundo tipo de notação encontra-se ligado à práxis do canto e à sua transmissão. Os sinais gráficos, os neumas, são em geral sobrepostos ao texto, conectando-se de maneira incindível à concreta sílaba a que se reportam (Kelly 2018, 239). Nas suas manifestações mais antigas não usa linhas de pauta ou claves: indica a direç̧ão fundamental do movimento melódico (subida, descida, repetição) e particularidades de execução rítmica e verbal ${ }^{48}$, mas não a altura precisa dos sons e os intervalos (notação adiastemática ou in

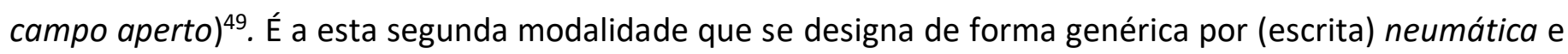

47 "Danach wäre die Notenschrift beides, Nachahmung der sogenannten Cheironomie eines Gestischen im wörtlichen Sinn und Abbild eines Disziplinären, der Lenkung des Chors durch den prähistorischen Dirigenten" (Adorno 2001, 230).

${ }^{48}$ Como escreve Susan Rankin $(2018,77)$ : "What the musical signs achieved was control of the reader's singing in very precise ways: which notes were linked with individual syllables, exactly how many notes fitted with each syllable and where the melody should move more or less emphatically.

49 São variadas as morfologias, que têm sido agrupadas sobretudo por critérios regionais: notação sangalense, bretã, lotaríngia, beneventana, etc. (Hiley 1993, 346-356). Esta diversidade morfológica suscita dúvidas sobre leituras de tipo causal-evolutivo, sustentado na derivação das formas musicais mais recentes 
é quanto a ela que o problema da origem da notação medieval é usualmente abordado (as "origens dos neumas").

10.

O tema do aparecimento da notação no contexto do canto litúrgico latino continua envolto em dúvidas e controvérsias; e das diversas hipóteses propostas nenhuma tem conseguido impor-se na comunidade científica (cf. Hiley 1993, 261-373; Ferreira 2002; Kelly 2018, 248-250; Rankin 2018). A posição mais consensual sustenta que os estratos mais antigos dos repertórios litúrgicos latinos se teriam constituído e transmitido ainda no contexto de uma cultura que desconhecia (ou não usava) sistemas de notação, dependendo a pervivência das melodias da pura tradição oral ${ }^{50}$. É bem conhecida a frase de Santo Isidoro de Sevilha, em pleno século VII, afirmando que a música dependia por inteiro da memória, porquanto não havia maneira de a escrever: Nisi enim ab homine memoria teneantur, soni pereunt, quia scribi non possunt (Etymologiarum III, 15). Em face disto, será caso para perguntar, com David Hiley $(2009,198)$ : se gerações de cantores conseguiram cantar sem notação qual foi o motivo que determinou a sua invenção ${ }^{51}$ Quando, como e por que razões terá ocorrido a passagem do "modelo" de oralidade para um outro que já conhece formas com escrita, e quais os mecanismos de articulação entre eles ?52

11.

Sobre o problema da invenção das grafias (como e porquê?) existem múltiplas hipóteses explicativas, nalguns casos em patente oposição, noutros, porém, com intersecções e complementaridades (Phillips

de outras mais antigas. Parte da doutrina tem sublinhado que as distintas "escolas de notação", partilhando embora princípios estruturantes similares, revelam variantes gráficas sensíveis, podendo ter surgido num curto período de tempo com alguma autonomia recíproca e, sobretudo, sem dependerem de um arquétipo ou modelo originário, do qual seriam cópias mais ou menos fiéis: teses poligenésicas ( $c f$. Phillips 2000, 433; Ferreira 2002, 15).

50 Essa transmissão oral seria mediada por cantores especializados dos mosteiros e das catedrais com longos anos de aprendizagem e prática quotidiana, capazes de executar de cor o vasto repertório (sobre a formação dos cantores medievais, v. Fassler 1985; Boyton 2000. Com profundidade sobre o tema da memória na cultura medieval, v. Carruthers 2008 e Berger 2005). Por outro lado, sob a diversidade de estilos e formas, determinada essencialmente pela função litúrgica pertinente a cada canto específico, detectam-se estruturas formulares, motivos rítmico-melódicos recorrentes que possibilitariam, no entender de muitos estudiosos, a sua expansão e disseminação ao longo do tempo mesmo sem suporte escrito (sobre o tema $v$. Karp 1998). Claro que em relação a este ponto os dados são muito ténues e não permitem conclusões seguras. Aliás, não se pode esquecer o perigo de uma ilegítima transposição temporal: as referidas estruturas formulares que se pretende constituirem traves-mestras do contexto de oralidade são identificadas em face do repertório notado.

51 "If generations of singers had managed without it, why was notation invented at all" (Hiley 2009, 198).

52 As perguntas enunciadas não podem receber aqui sequer um esboço de resposta - elas surgem (também) por causa das interrogações de Adorno sobre as "origens", sobre o porquê e para quê da criação de sistemas de notação - os problemas da constituição do repertório no contexto do império franco, das suas conexões com a tradição de Roma, os mecanismos de transmissão oral e da sua articulação com a notação, contam-se entre as mais controversas matérias da investigação musicológica, espelhada numa amplíssima literatura, impossível de recensear. Veja-se, entre muitos outros, Corbin, 1952; Treitler 1982, 1984; 1992; Levy 1987a; 1987b; 1990; Hucke 1980; Hughes 1987; Hucke 1988; Bernard 1996; Hornby 2004; Jeffery 1992; Karp 1998; Ferreira 2002; Boynton 2003; Pfisterer 2018; Rankin 2018. 
2000, 505-525; Hiley 1993, 361-373). Atendendo ao propósito que nos move neste trabalho (uma leitura das origens e funções da notação gregoriana à luz da teoria de Adorno), resumimos a exposição aos traços essenciais, sobretudo aos que se podem ligar mais directamente com a origem géstica ou quironómica dos neumas ${ }^{53}$.

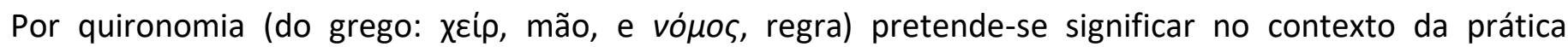
gregoriana o procedimento géstico pelo qual o regente do coro indica os movimentos rítmico-melódicos (a regra do canto imposta pela mão) ${ }^{54}$. Desta ideia de orientação gestual passou-se para a origem quironómica da notação neumática: ela seria a tradução sobre o pergaminho desses movimentos que o regente da schola cantorum traçaria no espaço durante a execução do canto e como meio de o controlar. A tese quironómica encontrou bastante ressonância na literatura. Entre os seus primeiros e mais estrénuos defensores, conta-se o fundador da Paléographie Musicale, o monge beneditino André Mocquereau (aliás invocado, como vimos, por Adorno, via Riemann). Num importante estudo inserido precisamente no volume inaugural daquela importante publicação em fac-símile de manuscritos medievais, Mocquereau distingue dois tipos fundamentais de notação: a notação oratória ou quironómica; e a notação musical ou diastemática. A primeira, que reputa a mais antiga, indicaria a direcção da linha melódica; os seus elementos gráficos, decorrentes embora das figuras gramaticais da acentuação ou prosódia, dirigem-se no essencial a imitar no pergaminho o "gesto oratório" (Mocquereau 1889, 97) ${ }^{55}$. Este gesto "é a representação plástica, o símbolo espontâneo dos sentimentos do orador. Na acção do discurso, a mão e a voz obedecem em simultâneo aos mesmos movimentos da alma: daí, a sua íntima conexão" ${ }^{56}$. No quadro

53 Além da teoria quironómica, outras teorias explicativas têm feito curso. Entre as mais disseminadas, estão as que fazem derivar os neumas dos sinais de pontuação usados para o texto literário ou, prevalentemente, dos acentos gramaticais (cf. Hiley 1993, 365-367; Phillips 2000, 516-519; Atkinson 1995; Rankin 2018, 25 ss). A relação entre sinais gramaticais e morfologia dos neumas tem sido muito analisada, sobretudo na notação sangalense, pelo número, antiguidade e profusão gráfica dos testemunhos. Parte-se da ideia de que os notadores se teriam inspirado nos grafemas dos acentos para significar os movimentos melódicos: som melodicamente mais elevado, acento agudo /: virga; som melodicamente mais grave, acento grave $\backslash$ - : punctum. Combinando estes sinais básicos, poderiam exprimir-se outros movimentos melódicos. Por exemplo: sucessão melódica agudo $\rightarrow$ grave: virga + punctum $(/+\backslash=\cap)$ : clivis; sucessão melódica grave $\rightarrow$ agudo: punctum + virga $(\backslash+/=\vee)$ : podatus. Todavia, e como sublinha Hiley $(2001, \S 3$ (iii)): "with the exception of Palaeo-Frankish neumes, the grave accent is hardly recognizable in most notations". Aliás, "[...] while the prosodic accents were certainly known in Carolingian times, they can have suggested hardly more than some rudimentary elements of a system for music notation". São numerosas as teorias ecléticas, que procuram articular diversos "modelos originantes", como, por exemplo, a proposta de Eugéne Cardine, para quem a neumática resultaria da combinação dos elementos gramaticais de pontuação e quironómicos (Cardine 1968, 4-5), ou a profunda construção de Keneth Levy, distinguindo dois tipos fundamentais de notação: posicional e gestual (Levy 1987a).

54 Note-se, todavia, que o uso da palavra com esta acepção é tardio, tendo surgido já no quadro de explicações teóricas quanto à origem dos neumas (Hugo 1963, 155).

55 "Ces accents grammaticaux, dont toutes les notations neumatiques \& modernes vont dériver, ne sont pas des signes adaptes par convention à la musique du langage, mais des figures issues comme naturellement de la mélodie oratoire, tracées à son image (du moins en ce qui concerne la mélodie des mots considérés en eux-mêmes), \&, par suite, admirablement appropriées à leur rôle \& à leur signification" (Mocquereau 1889, 98).

56 "Le geste est la représentation plastique, le symbole vivant \& spontané des passions de l'orateur, l'image des ondulations rythmiques \& mélodiques de la voix. Dans l'action du discours, la main \& la voix obéissent simultanément aux mêmes mouvements de l'âme: de là leur étroite connexion" (Mocquereau 1889, 98). 
da literatura germânica, a explicação quironómica teve grande relevo na obra de Fleischer (1895), que elevou a quironomia a uma lei universal ${ }^{57}$, e, embora de forma assaz mais contida, na magistral e influente Neumenkunde de Wagner $(1912,17)^{58}$.

Sabemos muito pouco sobre a práxis interpretativa - a tese géstica pressupõe uma direcção efectiva pouco documentada (Hugo 1963; Hucke 1979). Em seu favor, pode citar-se uma glosa presente em dois manuscritos do séc. $X$, conservados na Bibliothèque nationale de France, em que se regista: Motu id est gestu ut scilicet saltatrices et histriones et cantorum neuma - movimento isto é gesto, a saber, bailarinas, histriões e o neuma dos cantores ( $c f$. Ferreira 2002, 19). Mais expressivos, ainda, são dois incisos de um importante tratado musical: a Musica Disciplina, escrito por Aureliano de Réome em meados do século IX. Reportando-se aparentemente ao modo de executar uma figura musical, escreve Aureliano: percussoris ad instar manum vox erigitur e, noutro local, trina ad instar manus verberantis (cf. Phillips 2000, 507), parecendo sugerir que elevações melódicas (vox erigitur) e outros efeitos vocais seriam indicados pelo gesto da mão (ad instar manus). Aliás, como refere Hiley (1993, 370), tem-se feito algumas experiências a partir da notação de Saint Gall que indiciam ser possível replicar com o gesto os desenhos gráficos fundamentais, pelo que parece defensável o caminho inverso: que os neumas hajam sido originariamente a tradução gráfica dos movimentos de direcção.

No entanto, a multiplicidade de sinais encontrada dentro de cada sistema gráfico e as diversidades regionais de morfologias fragilizam a explicação quironómica: os gestos feitos pelo presumível regente coral teriam assim tantos cambiantes e tantas traduções gráficas distintas? Mais: para conseguir uma reprodução eficaz aproximada de tamanha variedade de neumas dispostos em sucessão contínua, os gestos não teriam de ser "perturbadoramente rápidos" (Hiley 2009, 198) ?59 Por outro lado, a circunstância de haver uma géstica de direç̧ão que conduzisse os cantores na performance não implica que esses gestos encontrassem uma tradução sígnica nos manuscritos, servindo como guião escrito de futuras interpretações, ou seja, que as figurações neumáticas que vemos registadas no pergaminho tivessem sido criadas como imagens do movimento da mão (cf. Hiley 2009, 198). Contra a teoria quironómica invoca-se ainda a circunstância de a notação neumática também surgir - e com uma riqueza de pormenores admirável - em peças de canto solístico (os versículos do Alleluia ou do Offertorium, p. ex.), casos que não precisariam de direcção géstica (Phillips 2000, 507) ${ }^{60}$. Diga-se, de todo o modo, que este argumento por si

57 "Wir sehen im 5.-7. Jahrhundert allerwärts, bei Juden, Griechen, Römern, Germanen, Slawen, in Europa und außerhalb Europas - fast in der ganzen gebildeten Welt von damals - das Streben auftauchen, die kirchlichen Vortragsbücher mit Neumenzeichen auszustatten. Aber niemand scheint es der Mühe für wert gehalten zu haben - weder mit direkten Erklärungen, und auch nur durch nebenhin geworfene Andeutungen - uns zu sagen, was sie bedeuten, wie sie heißen, woher sie stammen [...] Durch die Bewegungen der Hand konnte eine einfache Melodie in die Luft geschrieben werden. Von dieser bewegten Schrift zur unbewegten, auf Pergament fixierten war der Schritt nicht groß, und da die einzelnen Gebärden jener bewegten Schrift Neumen hießen, so erhielten nun auch die festen Zeichen der fixierten Schrift denselben Namen" (Fleischer 1895, 26).

58 "Alles zusammengenommen, leitet die Neumenschrift ihre Zeichen aus zwei Quellen ab: aus der Cheironomie und den Akzenten" (Wagner 1912, 17). Com mais desenvolvimento, v. Hucke 1979, 2 ss.

59 "It is certainly possible to imagine the St Gall or Laon neumes as the counterparts in writing of hand gestures, although the speed of the gestures would have to be disturbingly fast if the neumes were to be reproduced exactly in performance (at least, at what seems a reasonable singing pace)" (Hiley 2009, 198). 60 "bei solisticher Musik wie derjeningen im Cantatorium St. Gallen 359 war sie [die Cheironomie] gewi $\beta$ überflüssig" (Phillips 2000, 507). 
só não inviabiliza em definitivo a possível origem quironómica dos neumas. Pretendendo a notação conservar informação relevante para a prática, essa informação seria veiculada pelo cantor ou cantores principais da schola, alguns deles mesmo os solistas das obras mais complexas ${ }^{61}$. Logo, não seria descabido que na preparação individual e, sobretudo, no ensino dessas obras às novas gerações de intérpretes, se usasse a géstica como meio de transmissão de ideias e que essa géstica comunicacional se densificasse graficamente.

\section{2.}

A controvérsia em torno da origem histórica do sistema neumático e dos modos de constituição (da inventio) dos específicos sinais gráficos (o quando, onde e como) alarga-se em complexidade quando se considera o fundamento, o porquê e para quê desse "salto enorme" que a notação significou. Recordando a pergunta de Hiley $(2009,198)$ : "if generations of singers had managed without it, why was notation invented at all"? A questão assume maior relevo, ainda, quando se considere que nestas gerações de cantores não se contam somente as que usando o repertório se situam antes do "nascimento" da notação. Com efeito, mesmo depois, mesmo já havendo formas notacionais em uso e expansão, amplas regiões da cristandade medieva (incluindo a própria sede papal) terão mantido práticas musicais com conteúdos similares, embora sem suporte de grafias musicais ( $c f$. Hiley 1993, 346 ss). Ou seja: a difusão neumática a partir do século IX foi um processo não-linear, com assimetrias e alguns recuos, um processo que reflecte contextos político-sociais instáveis, marcados por invasões, anos de más colheitas e fomes, modificações na conjuntura dominial etc., mas que pode também significar que a "necessidade" da notação não terá sido sentida na mesma medida em regiões coetâneas próximas.

A pergunta permanece, de todo o modo: que necessidade, que função social se procurou realizar por meio destas primordiais técnicas de registar os cantos não somente na sua parte literária mas ainda com elementos gráficos que exprimem e remetem para dimensões musicais? A explicação funcional mais óbvia é que a escrita musical surge como uma aide-mémoire para os intérpretes: as dificuldades em memorizar um repertório em expansão teriam impulsionado primeiro a fixação dos textos e, mais tarde ${ }^{62}$, a criação de

\footnotetext{
${ }^{61}$ Cf. Hucke $(1980,448)$, ao referir que estes primeiros livros "seem to be archive manuscripts, which may have served as a reference for the cantor and as a control against deviation from the true and venerable tradition".

62 Não é fácil escapar à sedução da linearidade explicativa de que os fenómenos decorrem (apenas) por derivação progressiva: oralidade $\rightarrow$ escrita; neumas adiastemáticos $\rightarrow$ notação com claves e pautas; monodia $\rightarrow$ polifonia. No caso em apreço, a derivação seria: livros somente com os textos $\rightarrow$ livros de música. Mas como se sabe, a realidade é mais complexa, cruzando-se em múltiplas linhas. Entre os mais antigos manuscritos com o repertório gregoriano da Missa, contam-se, é certo, livros que apresentam só a parte textual dos cantos. Todavia, quando alguns deles foram escritos já a notação estava disponível e em uso, significando que a omissão de grafias musicais não foi imposta por carência, mas decidida por opção. $\mathrm{Na}$ verdade, outros motivos não estritamente musicais (no sentido de música para ser cantada) podem estar associados a alguns daqueles registos. Aliás, nem todos os livros se destinavam a ser efectivamente lidos, podendo desempenhar funções simbólicas, ou manifestar o estatuto social dos seus detentores, como ocorreu com diversos manuscritos ricamente decorados mas não dirigidos ao uso corrente, como o belíssimo Gradual de Monza (meados séc. IX), escrito com tinta de prata e ouro (chamando a atenção para este importante aspecto da função dos livros, $v$. Rankin 2018, 60).
} 
sinais gráficos capazes de "conservar" o estrato musical ${ }^{63}$. Tal como Adorno nos recordou (cf., supra, número 6), esta leitura traduz, porém, injustificada imposição de uma ideia do nosso tempo a um contexto cultural diverso. Pois bem: a investigação histórica focada precisamente sobre esse específico contexto medievo vem corroborar a crítica adorniana.

Importa não esquecer, com efeito, que tipo de informação se procurava conservar e veicular através das primeiras formas neumáticas. Ao invés do que modernamente se reputa como dimensão essencial da notação, já se explicitou que os neumas não visavam registar as concretas alturas melódicas. Nessa medida, a escrita musical não trouxe um imediato câmbio radical no paradigma da aprendizagem, interpretação e transmissão, mas um meio diferenciado em articulação com modelos de oralidade (cf. Rankin 2018, 77) ${ }^{64}$. Por isso, justificar a nova atitude que impulsionou a notação como um mero contrapeso do enfraquecimento da memória musical colectiva não se ajusta aos dados históricos (Rankin 2018, 341 $)^{65}$, que exigem uma análise mais alargada, que vá para além do fundamento utilitário (mnemónico).

\section{3.}

Como se compreende, a questão da datação dos primeiros espécimes notados tem condicionado as hipóteses explicativas ${ }^{66}$. De todo o modo, quer os testemunhos notacionais quer muitos outros elementos documentais remetem-nos para o âmbito da cultura carolíngia. Mesmo que não se aceite a importante hipótese sustentada por Kenneth Levy de que já por volta do ano 800 existiria uma versão notada do próprio da missa: um "arquétipo neumado carolíngio" (Levy 1987b) ${ }^{67}$, há evidência bastante quanto ao

63 Como resume Treitler $(2011,108)$ : "in modern studies of early music writing in the European Middle Ages, it has been virtually a commonplace to presume that the neumes by means of which liturgical and other songs were recorded functioned as (no more than) mnemonics for their singers".

64 Isto é assim claramente no repertório litúrgico já consolidado, em que os "graphic signs could act as stimuli in the process of reading, but they did not replace recall of an already known melody" (Rankin $2018,77)$; em relação a outro tipo de cantos, criados já em contexto de escrita, a situação podia ser diversa (cf. Idem, 77 ss, com análise da prósula Psalle modulamina).

65 Cf. Rankin 2018, 341: "To judge this new attitude as directly determined by reduced dependence on memory would be too easy and a misreading of the evidence".

${ }^{66}$ Não é o mesmo, com efeito, dizer que os vestígios mais antigos são datáveis de finais do século IX ou já das primeiras décadas desse século, uma vez que o contexto histórico, político, cultural e social se foi alterando ao longo desses anos e isso teve implicações no domínio da literacia. No entanto, e como se verá em texto, é essencial ter sempre presente que os fragmentos e livros com notação efectivamente identificados e datados constituem, somente, uma elemento para a compreensão deste complexo horizonte.

${ }^{67} \mathrm{Em}$ 1952, a eminente paleógrafa Solange Corbin havia escrito: "tout se passe comme s'il y avait eu un prototype dont nous ignorons tout, sauf qu'il a été reproduit de façon différente suivant les régions, que ces différences se produisent dès la fin du ix ${ }^{\mathrm{e}}$ siècle, et qu'elles ont conservé leurs caractères jusqu'à la fin du $x^{\mathrm{e}}$ siècle, parfois plus tard, et même lorsque les neumes ont pris place sur la portée" (Corbin 1952, 228). Levy aprofundou e fundamentou essa hipótese interpretativa, situando-a num contexto particularmente plausível, a corte carolíngia. Como sublinha Ferreira (2002, 16): "desde el punto de vista de la Historia Cultural, es fácil percibir e imaginar que la política religiosa de Carlomagno, que implicaba un esfuerzo sistemático de propagación de un modelo único para el culto litúrgico en su Imperio, pueda haber impulsado, a través de la invención de una técnica de escritura, el control de los contenidos musicales de esa liturgia. Es el momento histórico y el contexto adecuado para que algo así hubiese ocurrido. Un siglo 
interesse e acção em matéria de reforma litúrgica sobretudo durante os reinados de Pepino, o Breve, Carlos Magno e Luís, o Pio, que teria de se reflectir no corpus textual-melódico (cf. Hucke 1980; Hughes 1987; Levy 1987b; Hiley 1993, 514-523; McKitterick 2008).

Em conjugação com outros mecanismos administrativos, diplomáticos, militares, a tendencial uniformização litúrgica promovida pelos carolíngios concorria para organizar e disciplinar o vasto império (Levy 1987b; McKitterick 2008). Os intercâmbios políticos e culturais com a sede pontifícia romana, desde as famosas visitas do papa Estêvão II à corte de Pepino (753-54), culminando na solene coração imperial de Carlos Magno por Leão III, no Natal de 800, iam tendo reflexos sobre os conteúdos dos ritos ${ }^{68}$, $\operatorname{com}$ a assimilação de modelos romanos (Sacramentários, Lecionários, Graduais.... ${ }^{69}$. Uma reforma cultual requer muitos meios humanos e instrumentais. Requer formação especializada e instituições que a dinamizem; requer estratégias comunicacionais e simbólicas. Como se tem presente, no contexto epocal em que nos situamos, a liturgia (com o canto que nela se integra) não é uma dimensão secundária na realidade vivencial individual e colectiva: ela ergue pontes entre o reino terrestre e o transcendente. Por isso, é crucial a exactidão ritual, isto é, uma ortopraxis que exprima adequadamente os conteúdos da ortodoxia (lex orandi, lex credendi). Os valores simbólicos do mysterium repercutem-se (reclamam) os meios organizacionais e disciplinares que zelam pela correctio e excluem a déviance e o erro. Como sublinha justamente Rankin (2018, 341 ss), a cultura litúrgica carolíngia está particularmente atenta à necessidade de controlar e corrigir também o que se canta e como se canta e providencia os mecanismos institucionais adequados. A invenção e expansão dos neumas insere-se neste horizonte ${ }^{70}$, que expande as scholae cantorum e reforça a formação dos seus elementos (Cotreni 1995), que não se limita a "importar" livros litúrgicos de Roma mas que os ajusta, copia e dissemina por todo o império; insere-se nesta época de florescente literacia, capaz de construir e tornar dominante uma nova tipologia de escrita (a carolina

después, las condiciones sociales y políticas ya no eran tan propicias". Aliás, ao admitir-se aquele arquétipo notado, torna-se mais simples compreender o facto manifestamente impressionante de os manuscritos do séc. X e XI, escritos em locais muito diversos e com variantes gráficas sensíveis, registarem, no entanto, versões muito similares dos cantos - esta coincidência parece pressupor um exemplar originário que teria servido de matriz à disseminação do repertório nos territórios sob influência dos carolíngios (de novo, Ferreira 2002, 16). A teoria tem sido, no entanto, bastante contestada. Entre outros argumentos, e além do facto óbvio de não haver registo desse fonte primeva, realça-se a circunstância de os exemplos mais antigos de neumas que chegaram efectivamente até nós, datáveis das primeiras décadas do século IX, não se reportarem ao corpo central do repertório, mas surgirem associadas a formas litúrgico-textuais de criação mais recente, como a prósula Psalle modulamina (cf. Rankin 2019, 77-84) ou destinadas aos diáconos e presbíteros e, até, a cantos não-litúrgicos e obras polifónicas, e não (como parecia expectável) às partes muito mais complexas do coro ou do cantor-solista (Phillips 2000, 421-433). Isto parece indiciar que os primeiros esforços de notação teriam sido aplicada a cantos em que faltaria o apoio da tradição oral. Sobre o ponto, ver, ainda, Greyer 2003; Bernard 1996, 712-724; DiCenso 2017, 317-321.

68 O terreno da ritualidade é menos estável do que seria de esperar quando focamos o seu lado estrutural, a organização em sistemas simbólicos que tendem à reiteração no tempo. Porém, o facto de os "sentidos codificados" no ritual resultarem de sequências pré-fixadas (nessa medida, exteriores aos participantes), não significa que tais estruturas sejam uma espécie de frozen objects ou meras thougthless actions. Sobre o problema do ritual, numa perspectiva da antropologia cultural, $v$. a informada e reflexiva análise de Bell 2009, 13-66.

${ }^{69}$ Sobre a diversidade de livros litúrgicos v. Hiley 1993, 287-339.

70 Tem razão Susan Rankin $(2018,354)$ quando sublinha: "what could be achieved through these early examples of music writing is surely of considerably more interest - in view of the later history of musical notations - than the reason for the first step of invention having been taken". 
minúscula); e faz parte de um contexto cultural que, com o tempo, saberá expandir o repertório gregoriano, não só nos conteúdos e formas (sequências, novas festas etc.) mas ainda espacialmente, tornando-o hegemónico praticamente por toda a Europa ocidental.

\section{4.}

É tempo de concluir este breve percurso motivado pela leitura da Theorie des musikalischen Reproduktion de Adorno, que convidou a revisitar tópicos essenciais para quem se ocupa da monodia gregoriana. Em primeiro lugar, a questão da "origem dos neumas", ou melhor, das concretas grafias documentadas nos primeiros manuscritos litúrgicos adiastemáticos. Como vimos, a partir da reflexão sobre o sentido da notação, Adorno considera a quironomia como expressão de uma dimensão mais profunda inerente à linguagem musical e à sua escrita, a dimensão mimética, e que se traduz nos sinais neumáticos enquanto formas de representação estilizada de gestos de regência coral. O segundo tópico prende-se com as funções que, por meio da notação, se realizam socialmente, sublinhando que a escrita musical não decorre de uma intenção mnemónica, mas tem associada um pretensão de domínio e controlo.

Procurou-se visualizar essa questão no estrito quadro histórico do canto litúrgico medieval. Por um lado, a "invenção dos neumas" (documentados desde primeiros décadas do século IX) não se destinou prioritariamente a auxiliar a memorização dos cantos. Por outro lado, a neumática não pode ter passado à margem do profundo projecto político-litúrgico do período carolíngio - a consciência nítida que os dirigentes carolíngios tinham de que a imposição de uma liturgia unificada, quer nas formas textuais e rituais quer, naturalmente, nas expressões musicais que as integravam, constituía um meio necessário e eficaz para a edificação de um império, reclamaria instrumentos adequados. E nessa medida, a neumática representou um instrumento de controle e domínio.

A obra de Adorno não se enquadra nos parâmetros metodológicos usuais na musicologia histórica: há sobreposição de planos temporais, sem balizas ou marcos cronológicos claros, há inusitadas interpenetrações de abordagens históricas e antropológicas ${ }^{71}$. Mas essa "resistência", julgamos, torna-a (também) historiograficamente interpelante.

\section{Referências}

Adorno, Theodor W. 1978a [1965]. "Über einige Relationen zwischen Musik und Malerei". In Gesammelte Schriften editado por Rolf Tiedemann. Frankfurt am Main: Suhrkamp, 1970-1997, Band 16 (1978): 628-642. [há tradução para inglês: "Music, Language, and Composition", traduzido por Susan Gillespie. The Musical Quarterly 79 (1995): 66-79].

Adorno, Theodor W. 1978b [1956]. "Musik, Sprache, und ihr Verhältnis im gegenwärtigen Komponieren". In Gesammelte Schriften, editado por Rolf Tiedemann. Frankfurt am Main: Suhrkamp, 1970-1997, Band 16 (1978): 649-664. [há tradução para inglês: "Music, Language, and Composition", traduzido por Susan Gillespie. The Musical Quarterly 77 (1993): 401-414].

\footnotetext{
${ }^{71}$ Bastaria recordar como, a propósito da mimesis, a Theorie recua a tempos originários ou, melhor, préracionais, ou as reiteradas referências aos povos primitivos (den Primitiven), aos selvagens (Wilden), às barbarischen Kulturen, à dimensão cúltica da tribo (Stamm) (cf. (Adorno 2001, 69-70, 226-227). Ou, ainda, quando, considera que a intencionalidade da música é consequência da cristianização da música sem que se concretize a que épocas ou circunstâncias se está concretamente a pressupor.
} 
Adorno, Theodor W. 2001. Zu einer Theorie der musikalischen Reproduktion: Aufzeichnungen, ein Entwurf und zwei Schemata, editado por Henri Lonitz. Frankfurt am Main: Suhrkamp. [há tradução para inglês. Adorno, Theodore W. 2006. Towards a theory of musical reproduction: notes, a draft, and two schemata, editado por Henri Lonitz, traduzido por Wieland Hoban. Cambridge: Polity Press].

Atkinson, Charles M. 1995. "De accentibus toni oritur nota quae dicitur neuma: Prosodic Accents, the Accent Theory, and the Paleofrankish Script". In: Essays on Medieval Music in Honor of David G. Hughes, editado por G. M. Boone. Cambridge, MA: Harvard University Press: 17-42.

Aubert, Eduardo Henrik. 2012. "Historicizing Neumatic Notation: Medieval Neumes as Cultural Artefacts of Early Modern Times". Studies in Medievalism 21: 65-87.

Aubert, Eduardo Henrik. 2013. "When the Roman liturgy became Frankish - sound, performance and sublation in the eighth and ninth centuries". Études grégoriennes 40: 57-160.

Barry, Barbara. 2009. “In Adorno's Broken Mirror: Towards a Theory of Musical Reproduction”. IRASM 40, 1: 81-98.

Bell, Catherine. 2009, Ritual Theory, Ritual Practice. Oxford: Oxford University Press.

Berger, Anna Marie Busse. 2005. Medieval Music and the Art of Memory. Berkeley, Los Angeles: California University Press.

Bernard, Philippe. 1996. Du chant romain au chant grégorien. Paris: Cerf.

Boorman, Stanley. 2001. "The Musical Text". In Rethinking Music, editado por N. Cook and M. Everist. Oxford: Oxford University Press: 403-423.

Boynton, Susan. 2000. "Training for the Liturgy as a Form of Monastic Education". In Medieval Monastic Education and Formation, editado por George Ferzoco and Carolyn Muessig. Leicester: Leicester University Press: 7-20.

Boynton, Susan. 2003. "Orality, Literacy, and the Early Notation of the Office Hymns". Journal of the American Musicological Society 56 (1): 99-168.

Cahn, Michael. 1984: "Subversive Mimesis: Theodor W. Adorno and the Modern Impasse of Critique". In Mimesis in Contemporary Theory I: the Literary and Philosophical Debate. Philadelphia / Amsterdam: John Benjamin's: 27-64.

Cardine, Eugène. 1968. Semiologia gregoriana. Roma: PIMS.

Carruthers, Mary. 2008. The Book of Memory. A Study of Memory in Medieval Culture, 2nd ed. New York: Cambridge University Press.

Carvalho, Mário Vieira de. 2007. "A Partitura como Espírito Sedimentado: Em Torno da Teoria da Interpretação Musical de Adorno". In Interpretação Musical Teoria e Prática, editado por F. Monteiro e A. Martingo. Lisboa: Edições Colibri: 15-36.

Carvalho, Mário Vieira de. 2009. "Meaning, Mimesis, Idiom: On Adorno's Theory of Musical Performance". In Expression, Truth, Authenticity: On Adorno's Theory of Music and Musical Performance, editado por M. V. Carvalho. Lisboa: Edições Colibri: 83-94.

Carvalho, Mário Vieira de. 2012. "Musical Autonomy as a Referential System". In Music and its Referential Systems, editado por Matjaž Barbo e Thomas Hochradner. Wien: Hollitzer Wissenschaftsverlag: 1-20. 
Cecchi, Alessandro. 2017. "To imitate all that is hidden. The place of mimesis in Adorno's theory of musical performance". Aisthesis 1(1): 131-138.

Contreni, J. J. 1995. "The Carolingian Renaissance: education and literary culture". In The New Cambridge Medieval history. II: c. 700-c. 900, editado por R. McKitterick. Cambridge: Cambridge University Press: 709-57.

Cook, Nicholas. 2013. Beyond the Score: Music as Performance. Oxford: Oxford University Press.

Corbin, Solange. 1952. "Les notations neumatiques à l'époque carolingienne". Revue d'Histoire de l'Église de France 38: 225-232.

DiCenso, Daniel J. 2017. "Revisiting the Admonitio generalis." In Chant, Liturgy and the Inheritage of Rome. Essays in Honour of Joseph Dyer, editado por D. J. DiCenso e R. Maloy. Woodbridge: The Boydell Press: 315-371.

Dreyfus, Laurence. 1983. "Early Music Defended against Its Devotees: A Theory of Historical Performance in the Twentieth Century". The Musical Quarterly 69 (3): 297-322.

Duarte, Rodrigo A. de Paiva. 1993. Mímesis e racionalidade. A concepção de domínio da natureza em Theodor W. Adorno. S. Paulo: Edições Loyola.

Everist, Mark / Kelly, Thomas Forrest (ed.) (2018). The Cambridge History of Medieval Music, Cambridge: Cambridge University Press.

Fassler, Margot E. 1985. "The Office of the Cantor in Early Western Monastic Rules and Customaries: A Preliminary Investigation". Early Music History 5: 29-51.

Ferreira, Manuel Pedro. 2002. "La emergencia de la escrita musical". Media Aetas, 5: 11-32.

Fleischer, Oskar. 1895. Neumen-Studien. Abhandlungen über mittelalterliche Gesangs Tonschriften. Theil 1. Über Ursprung und Entzifferung der Neumen: Leipzig: Verlag von Friderich Fleischer.

Fubini, Enrico. 2004. "Temporalité de la musique et notation musicale: à l'origine du problème de l'interprétation". Musicae Scientiae 8: 21-35.

Greyer, James. 2003. "Adémar de Chabannes, Carolingian Musical Practices, and Nota Romana". Journal of the American Musicological Society 56 (1): 43-98.

Hiley, David. 1993. Western Plainchant. A Handbook. Oxford: Oxford University Press.

Hiley, David. 2001. "Western Plainchant. Notation, §III". New Grove Dictionary of Music and Musicians, 2nd ed., vol. XVIII, Oxford: Oxford University Press: 84-119.

Hiley, David. 2009, Gregorian Chant, Cambridge: Cambridge University Press.

Hornby, Emma. 2004. "The Transmission of Western Chant in the 8th and 9th Centuries: Evaluating Kenneth Levy's Reading of the Evidence". Journal of Musicology 21: 418-57.

Hucke, Helmut. 1979. "Die Cheironomie und die Entstehung der Neumenschrift". Die Musikforschung 32: 1-16.

Hucke, Helmut. 1980. "Toward a New Historical View of Gregorian Chant". Journal of the American Musicological Society 33: 437-467.

Hucke, Helmut. 1988. “Gregorianische Fragen”. Die Musikforschung 41: 304-330. 
Hughes, David G. 1987. "Evidence for the Traditional View of the Transmission of Gregorian Chant". Journal of the American Musicological Society 40: 377-404.

Huglo, Michel. 1963. "La chironomie médiévale". Revue de musicology 49: 155-171.

Jeffery, Peter. 1992. Re-Envisioning Past Musical Cultures. Ethnomusicology in the Study of Gregorian Chant. Chicago: The University of Chicago Press.

Karp, Theodore. 1998. Aspects of Orality and Formularity in Gregorian Chant. Evanston: Northwestern University Press.

Kelly, Thomas Forrest. 2018. "Notation I". In The Cambridge History of Medieval Music, editado por M. Everist e T. F. Kelly, vol. I. Cambridge: Cambridge University Press: 236-262.

Kuehn, Frank Michael Carlos. 2010. A Teoria da Reprodução Musical de Theodor Adorno e o legado da tradição vienense: uma introdução. Dissertação de doutorado em Música. Universidade Federal do Estado do Rio de Janeiro, Rio de Janeiro.

Levy, Kenneth. 1987a. “On the Origin of Neumes". Early Music History 7: 59-90.

Levy, Kenneth. 1987b. "Charlemagne's Archetype of Gregorian Chant". Journal of the American Musicological Society 40: 1-30.

Levy, Kenneth. 1990. “On Gregorian Orality". Journal of the American Musicological Society 43:185-227.

Lonitz, Henri (2001). "Editorische Nachbemerkung" in Adorno, Theodor W. 2001. Zu einer Theorie der Musikalischen Reproduktion: Aufzeichnungen, ein Entwurf und zwei Schemata, Frankfurt am Main: Suhrkamp.

McKitterick, Rosamond. 2008. Charlemagne. The Formation of a European Identity. Cambridge: Cambridge University Press.

Mocquereau, André. 1889. "Origine et classement des differentes écritures neumatiques". Paléographie Musicale, vol. I, Solesmes: Imprimerie Saint Pierre: 96-160.

Mocquerau, André. 1908. Le Nombre Musical Grégorien, vol. I, Rome, Tournai: Desclée.

Paddison, Max. 1991. "The Language-Character of Music: Some Motifs in Adorno", Journal of the Royal Musical Association 116 (2): 267-279.

Paddison, Max. 2004. "Performance, Reification, and Score: The Dialectics of Spatialization and Temporality in the Experience of Music". Musicae Scientiae 8: 157-179.

Paddison, Max. 2010. "Mimesis and the Aesthetics of Musical Expression". Music Analysis 29: 126-148.

Pfisterer, Andreas. 2018. "Origins and Transmission of Franco-Roman Chant". In The Cambridge History of Medieval Music, editado por M. Everist e T. F. Kelly, vol. I, Cambridge: Cambridge University Press: 6991.

Phillips, Nancy. 2000. "Notationen und Notationslehre von Boethius bis zum 12. Jahrhundert". In Geschichte der Musiktheorie, Bd. 4. Die Lehre von einstimmigen liturgische Gesang, editado por M. Huglo, C. Atkinson, C. M. Meyer, K. Schlager und N. Phillips. Darmstadt: Wissenchaffliche Buchgesellschaft: 293-635.

Rankin, Susan. 2018. Writing Sounds in Carolingian Europe: The Invention of Musical Notation. Cambridge: Cambridge University Press. 
Riemann, Hugo. 1919. Handbuch der Musikgeschichte. I. Band, I. Teil: Die Musik des klassischen Altertums, 2. Aufl., Leizig: Breitkopf \& Härtel.

Riemann, Hugo. 1920. Handbuch der Musikgeschichte, I. Band, II. Teil. Die Musik des Mittelalters, 2. Aufl. Leipig: Breitkopf \& Härtel.

Steiner, George. 1983. Presenças Reais (trad. de M. S. Pereira). Lisboa: Editorial Presença.

Treitler, Leo. 1982. "The Early History of Music Writing in the West". Journal of the American Musicological Society 35: 237-279. [rep. with a new introduction in: Idem, With Voice and Pen: 317-364].

Treitler, Leo. 1984. "Reading and Singing: On the Genesis of Occidental Music-Writing". Early Music History 4: 135-208. [rep. with a new introduction and a postcript in: Idem, With Voice and Pen: 365-428].

Treitler, Leo. 1992. “The 'Unwritten' and 'Written Transmission' of Medieval Chant and the Start-up of Musical Notation. Journal of Musicology 10: 131-191.

Treitler, Leo. 2003. With Voice and Pen. Coming to Know Medieval Song and How it Was Made. Oxford / New York: Oxford University Press.

Treitler, Leo. 2011. "What Kind of Thing is Musical Notation?", In Idem, Musical Meaning and its Representations. Bloomington e Indianapolis: Indiana University Press: 107-160.

Treitler, Leo. 2012. "Memoria and Mimesis". Nottingham Medieval Studies 56: 377-397.

Wagner, Peter. 1912. Einführung in die Gregorianischen Melodien. 2. Neumenkunde. Paläographie des liturgischen Gesanges, 2. Aufl. Leipzig: Breitkopf \& Härtel. 